\title{
Developmental Changes in the Neutral $\alpha$-Amino Acid Transport Systems of Rat Brain Over the First Three Weeks After Birth
}

\author{
Thomas R. Riggs, Kenneth G. Pote, Hae-Sook Im, and Daniel W. Huff \\ Department of Biological Chemistry, The University of Michigan, Ann Arbor, Michigan, U.S.A.
}

\begin{abstract}
Transport of seven different amino acids into brain slices increased as donor rats aged from 1 to 6 days. Uptakes of 2-aminoisobutyric acid, 2-(methylamino)isobutyric acid, and L-alanine then decreased by day 14 , while uptakes of other amino acids continued to increase or remained fairly constant. Neutral $\alpha$-amino acid transport systems were characterized by measuring inhibition of uptakes and kinetics for representative amino acids at different ages. Results indicate that 2-aminoisobutyrate and 2-(methylamino)isobutyrate used only one (and the same) system in brain slices from 6-day-old rats, with characteristics of system $A$ (the major sodiumdependent system in most mammalian cells). They used at least two systems at ages 1, 14, and 23 days, but, of these, only at 1 day did they use the same systems in the
\end{abstract}

same proportions. Alanine and leucine used more than one system at all four ages, and somewhat different combinations than used by each other or by 2 -aminoisobutyrate or 2-(methylamino)isobutyrate. Their transport characteristics showed they used mostly system ASC (a sodium-dependent system distinguished from A) and/or system $\mathbf{L}$ (sodium-independent). We conclude that system $A$ increases as the brain ages from 1 to 6 days and declines thereafter. System $L$ probably increases with aging from 1 to 23 days. Key Words: Brain-Transport systems-Development-Amino acids-Rats. Riggs T. R. et al. Developmental changes in the neutral $\alpha^{-}$ amino acid transport systems of rat brain over the first three weeks after birth. J. Neurochem. 42, 1251-1259 (1984).
Although several studies have described the general changes in amino acid transport in brain slices during development (Levi, 1973; Piccoli, 1976; Sershen and Lajtha, 1979), no detailed examination has yet been made of the transport systems for neutral amino acids at different times after birth of the rat. Changes in amino acid transport would be expected during growth and development of the brain in association with the altered requirement for protein synthesis during this time. In addition, it is during its development that brain is especially sensitive to changes in physiological conditions, such as thyroid hormone supply. Since this latter hormone is known to alter protein synthesis in developing brain (Gelber et al., 1964; Geel et al., 1967), the amount of thyroid hormone would be expected also to modify the transport of at least some of the amino acids into this tissue.

In the rat the major development of brain occurs over the first 20 days after birth (Dobbing, 1971). It is also over this time that brain development is influenced by thyroid hormone (Hamburgh et al., 1964). We have undertaken, therefore, a more detailed study of the changes that occur in amino acid transport over this time period in brains from normal and hyperthyroid rats. The present paper examines the effects of development on transport of several amino acids in brain slices from normal rats of different ages from birth to 3 weeks old and describes some changes in neutral $\alpha$-amino acid transport systems that normally take place over this age. In a separate paper we describe the effects of
Received July 26, 1982; revised August 2, 1983; accepted October 21, 1983.

Address correspondence and reprint requests to Dr. Thomas R. Riggs, Department of Biological Chemistry, The University of Michigan, Ann Arbor, MI 48109, U.S.A.
Abbreviations used: AIB, 2-Aminoisobutyric acid; Cycloleucine, 1-Aminocyclopentane carboxylic acid; MeAIB, 2-(Methylamino)isobutyric acid. 
thyroxine on uptake of amino acids by brain slices at these ages and show some of the changes that occur in the transport systems when rats are given thyroxine (Riggs et al., 1984).

\section{MATERIALS AND METHODS}

Near-term pregnant rats derived from the SpragueDawley strain were obtained from Spartan Research Animals, Haslett, MI, or Charles River Breeding Laboratories, Portage, MI. When pups were born, each litter was maintained at a size of 8-10 animals. Rats were used at different ages after birth, and unless other specific ages are given, the results for convenience were grouped from animals in five age ranges: 1-day group, rats from birth up to 24 h old; 6-day group, rats 5-7 days old; 10-day group, those 10 or 11 days old; 14-day group, those 1315 days old; and 23-day group, those 22-24 days old.

Brain slices were prepared by decapitating the rats, dissecting out the cerebellum, and slicing the cerebral hemispheres on a Mcllwain tissue chopper (New Brunswick) to a thickness of $0.4 \mathrm{~mm}$. Slices were suspended in $12 \mathrm{ml}$ of buffered Krebs-Ringer solution ( $\mathrm{pH}$ 7.4) containing $10 \mathrm{~m} M$ glucose and a ${ }^{14} \mathrm{C}$-labelled amino acid (New England Nuclear) and incubated in a $37^{\circ} \mathrm{C}$ shaker bath with reciprocal shaking at 100 strokes/min. For most experiments, the buffer medium was $25 \mathrm{~m} M$ bicarbonate gassed with $5 \% \mathrm{CO}_{2}-95 \% \mathrm{O}_{2}$. In studies of the effects of $\mathrm{pH}, 0.01 M$ phosphate buffer was used, and the gas was $100 \% \mathrm{O}_{2}$

At the end of the incubation period, the medium was filtered by suction, and brain slices were blotted on filter paper and treated with 20 volumes of $0.005 M$ acetic acid for $10 \mathrm{~min}$ in a boiling water bath. Filtered media were boiled with two volumes of $0.05 M$ acetic acid. Solutions were allowed to cool and then filtered. Aliquots were counted in a liquid scintillation spectrometer (Packard Tri-Carb).

Intracellular concentrations of amino acids were calculated on the basis of intracellular water, obtained after subtracting the amount of radioactivity in the extracellular fluid of the tissue from that in total tissue water. Total tissue water was obtained by dry weight determination $\left(105^{\circ} \mathrm{C}, 16-20 \mathrm{~h}\right.$, to a constant weight) following a 30 min incubation in the Krebs-Ringer bicarbonate medium. Extracellular fluid content was determined by the space filled by ${ }^{14}$-C-labelled sucrose following $30 \mathrm{~min}$ incubation under the same conditions used for amino acid uptake. Thiosulfate space was measured occasionally and was found to agree well with values for sucrose space. Calculations were made with values for water content and distribution as determined for each age and condition studied. Results are expressed as the distribution ratio, which is the ratio of the level of labelled amino acid in intracellular water to that in extracellular water.

\section{RESULTS}

Changes in water content and distribution in brain slices with age and after treatment with thyroxine or propylthiouracil

Total water content of the brain decreased regularly from about $90 \%$ in 1-day rats (Fig. 1) and fell

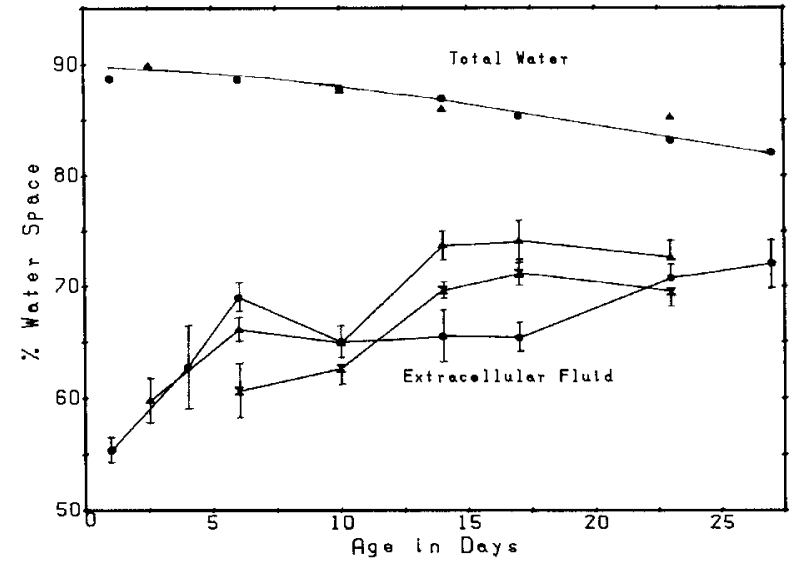

FIG. 1. Total tissue water and extracellular fluid space in brain slices from rats of different ages; effects of treatment with thyroxine and propylthiouracil. Dry weight (for total tissue water) and $\left[{ }^{14} \mathrm{C}\right]$ sucrose space (for extracellular space) were determined on brain slices after a 30 min incubation in normal Krebs-Ringer bicarbonate medium. Rats in the thyroxine and propylthiouracil groups were given these agents as described in Riggs et al. (1984). Values are averages \pm SEM for 2-20 samples per group. The vertical bars represent one standard error on each side of the average value. control; $\boldsymbol{\Delta}$, thyroxine-treated; $X$, propylthiouracil-treated. Adult control rat brains had a total tissue water of $78.8 \pm$ $0.5 \%$ and an extracellular fluid space of $72.7 \pm 3.0 \%$.

to below $80 \%$ in adults. Similar values were found in the saline- and thyroxine-treated groups. Extracellular space (calculated as percent of total tissue water after a 30 min incubation) increased significantly between 1 and 6 days in all groups. In the control group, the value then remained constant at about $65 \%$ until approximately day 18 , after which it increased to above $70 \%$ (Fig. 1). Treatment of donor rats with thyroxine or propylthiouracil produced an earlier increase in extracellular fluid space, the maximum value of a little above $70 \%$ being reached by 14 days of age (Fig. 1).

Transports of amino acids into brain slices from rats of different ages

All seven amino acids tested showed lowest uptake in 1-day-old tissues, with significant increase over the first 6 days after birth. When measured at 0.5-1 mM levels for $1 / 2 \mathrm{~h}$, transports of 2-aminoisobutyric acid (AIB), 2-(methylamino)isobutyric acid (MeAIB), and L-alanine declined thereafter (Table 1). Uptakes of 1-aminocyclopentane carboxylic acid (cycloleucine) and L-valine remained fairly constant, whereas those of L-leucine and L-glutamate rose slowly with age (tested up to 23-30 days, Fig. 2). When AIB was tested at various levels, however, less uptake was found in the 14-day-old tissues than at 6 days only at levels below about 15 $\mathrm{m} M$. These differences were found to be due to a change in kinetics of AIB uptake between 6 and 14 days (see below). MeAIB uptake, in contrast, was less at 14 days than at $\mathbf{6}$ days at all levels tested. 
TABLE 1. Transport of $A I B, M e A I B$, and alanine into brain slices from rats at ages $1,6,14$, and 23 days

\begin{tabular}{cccc}
\hline & \multicolumn{3}{c}{ Distribution ratio for: } \\
\cline { 2 - 4 } Age in days & AIB & MeAIB & Alanine \\
\hline 1 & $10.45 \pm 0.85(14)$ & $8.92 \pm 0.33(16)$ & $14.73 \pm 0.28(33)$ \\
6 & $24.57 \pm 0.87(29)^{a}$ & $13.35 \pm 0.68(17)^{a}$ & $27.67 \pm 0.62(29)^{a}$ \\
14 & $19.05 \pm 1.00(18)^{a}$ & $9.47 \pm 0.24(18)^{a}$ & $18.75 \pm 0.51(40)^{a}$ \\
23 & $16.69 \pm 0.37(25)^{b}$ & $9.38 \pm 0.47(10)$ & $14.91 \pm 0.37(49)^{a}$ \\
\hline
\end{tabular}

All incubations were for $30 \mathrm{~min}$ in Krebs-Ringer bicarbonate medium with a $1 \mathrm{mM}$ level of amino acid. Values are average \pm SEM for the number of samples shown in parentheses for each group.

${ }^{a} \mathrm{p}<0.001$ versus value for next youngest age (line immediately above).

${ }^{b} \mathrm{p}<0.02$ versus value for brain slices from 14-day-old rats.

\section{Uptake of AIB and MeAIB with time in brain slices of different ages}

Figure 3 shows that uptake of AIB and MeAIB did not decline from linearity for at least $30 \mathrm{~min}$ at all ages studied. However, the uptake curve for MeAIB in 6-day tissues showed a lag over the first 5-10 min. This lag is similar to that reported earlier for AIB uptake by the immature rat uterus (Riggs and Pan, 1972) and can be attributed to a derepression of uptake. This phenomenon has been found to occur in many tissues following incubation in amino acid-free media and has been associated with an increased activity of transport system A (Guidotti et al., 1978).

\section{Effect of a preliminary incubation on amino acid uptake}

This derepression of uptake was examined in more detail by measuring transports of both AIB and MeAIB following a $3 \mathrm{~h}$ preincubation of brain slices in amino acid-free buffer media. Under these conditions AIB showed an increased uptake in tissues from rats of $1,6,14$, and 23 days of age (Fig. 4), while MeAIB uptake was increased significantly

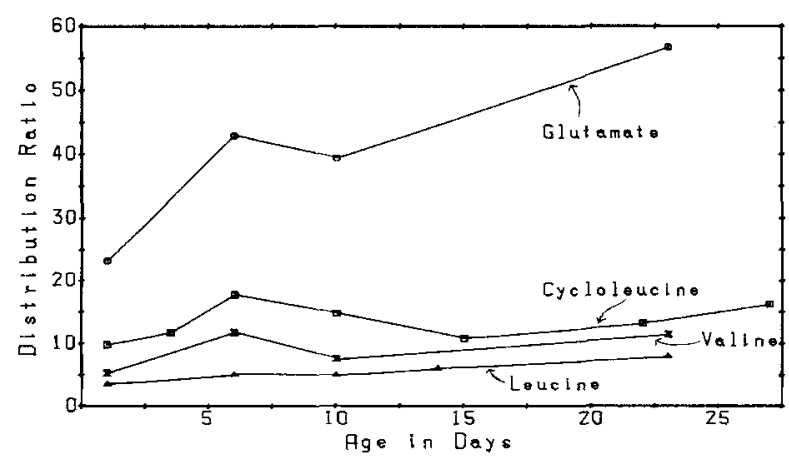

FIG. 2. Uptake of glutamate, cycloleucine, valine, and leucine by brain slices from rats of different ages. Uptake of a $1 \mathrm{mM}$ level of the amino acid was measured for $30 \mathrm{~min}$ in a normal Krebs-Ringer bicarbonate medium in each case. Values are averages for 4-8 samples each with glutamate, 3-8 samples each with cycloleucine, 4-15 values each with valine, and $4-10$ values each with leucine. at 6 days $(+39 \% ; \mathrm{p}<0.001)$, but not at 23 days. L-Leucine uptake was not altered by preincubation of 6-day-old brain slices.

Identification of neutral $\alpha$-amino acid transport systems in brain slices at different ages

The changes in transport as the brain developed (Table 1, Fig. 2) suggest that the transport systems in the tissues change over the first three weeks after birth. We therefore characterized the transport systems for the neutral $\alpha$-amino acids at four different times over this period, at ages $1,6,14$, and 23 days. For this purpose inhibition studies were carried out on four test amino acids chosen to discriminate among the transport systems: MeAIB, whose uptake in most tissues is believed to be limited mostly or entirely to system A; alanine, which would be expected to use system ASC extensively; leucine, as a representative for system L; and AIB, which
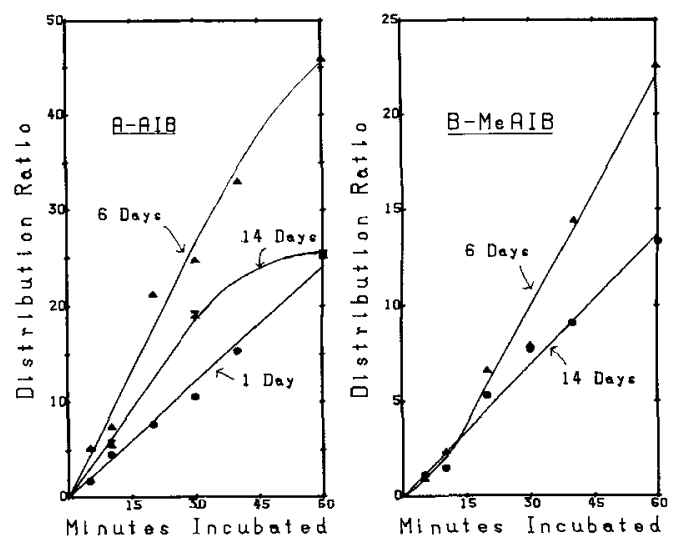

FIG. 3. Time curves of uptakes of $A \mid B$ and MeAIB by brain slices from rats of different ages. Both amino acids were used at $1 \mathrm{mM}$, and uptakes were measured from normal Krebs-Ringer bicarbonate medium. A: Values of AlB uptake are averages of 2-29 samples each. The line for the 1-day values was calculated by the method of least squares from all 6 points; for 6 days, the 40 and 60 min points were not used for a similar calculation. B: Values of MeAIB uptake are averages of 2 samples/point. The lines were calculated by the method of least squares with all 6 points from 14-day tissues, but with omission of the 5 min point at 6 days. 


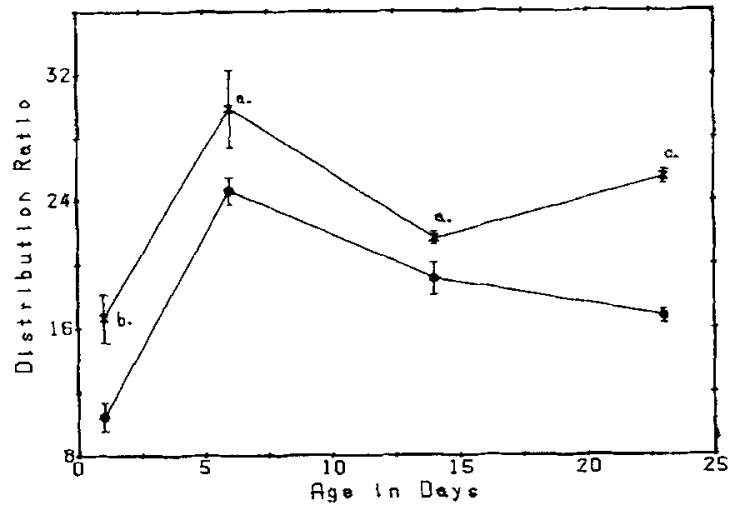

FIG. 4. Effect of a preliminary incubation on uptake of $A \mid B$ by brain slices from rats of different ages. Test slices $(x)$ were incubated in amino acid-free Krebs-Ringer bicarbonate medium for $3 \mathrm{~h}$, then transferred to fresh medium containing 1 $\mathrm{mM}\left[{ }^{14} \mathrm{C}\right] \mathrm{AlB}$, and uptake was measured for $30 \mathrm{~min}$. Control uptake (1) was measured without the $3 \mathrm{~h}$ preincubation. Values are averages \pm SEM for 6-29 samples in each case Statistical comparisons, preincubated versus control: ap $<0.02 ;{ }^{b} p<0.01 ;{ }^{c} p<0.001$.

has been used widely as a model for system A, but usually has been found to use system $\mathrm{L}$ and perhaps system ASC to some extent also (Christensen, 1975).

The results (Tables $2-5$ ) demonstrate the presence of the above three transport systems for neutral $\alpha$-amino acids. The presence of the sodium-de- pendent systems $\mathrm{A}$ and/or ASC was shown at all ages by decreases of $75-90 \%$ or more in uptakes of AIB, MeAIB, and alanine when $\mathrm{Na}^{+}$-free media were used. In addition, AIB and MeAIB uptakes were very sensitive to a decrease in incubation temperature and generally were inhibited more strongly by AIB, MeAIB, and alanine (A-system amino acids) than by leucine, valine, and phenylalanine (L-system amino acids). These are distinguishing characteristics of system A. Alanine uptake showed less sensitivity to temperature or addition of AIB and MeAIB than did the latter two amino acids, properties characteristic of transport system ASC. Leucine transport, in contrast, showed only moderate sensitivity to most inhibitory conditions at one age or another, but showed more $\mathrm{Na}^{+}$-independent uptake than did the other amino acids. This latter characteristic, especially, distinguishes transport by system L.

The results of Tables 2-5 also show a number of systematic changes in the inhibitory pattern for each test amino acid as the age of the donor rat increased, a fact demonstrating that changes occurred in the transport systems over the period of 1-23 days. Most striking among these changes are the increases with age in inhibition of AIB transport by leucine, isoleucine, valine, phenylalanine, MeAIB, or proline (Table 2, lines $10-13,5$, and 8); the decline with age in inhibition of MeAIB uptake

TABLE 2. Inhibition of AIB transport by different agents and conditions in brain slices from rats aged $1,6,14$, and 23 days

\begin{tabular}{|c|c|c|c|c|c|c|c|}
\hline \multirow[b]{2}{*}{ Inhibitor } & \multicolumn{7}{|c|}{$\%$ Inhibition of AIB uptake at age } \\
\hline & 1 Day & 6 Days & $\begin{array}{l}p \text { versus } \\
1 \text { day }\end{array}$ & 14 Days & $\begin{array}{c}p \text { versus } \\
6 \text { days }\end{array}$ & 23 Days & $\begin{array}{l}p \text { versus } \\
14 \text { days }\end{array}$ \\
\hline $\begin{array}{l}\mathrm{Na}^{+} \text {-free medium } \\
\text { Incubate at } 18^{\circ} \mathrm{C} \\
\text { pH } 5.4 \text { (Pi buffer) }\end{array}$ & $\begin{array}{l}74 \pm 1.1(9) \\
88 \pm 0.7(14) \\
49 \pm 2.7(4)\end{array}$ & $\begin{array}{l}86 \pm 1.1(10) \\
85 \pm 0.9(18) \\
49 \pm 5.9(8)\end{array}$ & $\begin{array}{l}<0.001 \\
<0.05 \\
\text { n.s. }\end{array}$ & $\begin{array}{l}88 \pm 0.5(16) \\
79 \pm 0.8(46) \\
32 \pm 1.1(7)\end{array}$ & $\begin{array}{l}<0.05 \\
<0.001 \\
<0.02\end{array}$ & $\begin{array}{l}83 \pm 0.7(9) \\
85 \pm 1.4(6) \\
46 \pm 2.6(4)\end{array}$ & $\begin{array}{l}<0.001 \\
<0.02 \\
<0.001\end{array}$ \\
\hline $\begin{array}{l}10 \mathrm{~m} M \text { AIB } \\
20 \mathrm{~m} M \text { MeAIB } \\
10 \mathrm{~m} M \text { Alanine }\end{array}$ & $\begin{array}{l}75 \pm 4.9(6) \\
33 \pm 4.4(4) \\
83 \pm 0.4(5)\end{array}$ & $\begin{array}{l}85 \pm 0.6(4) \\
59 \pm 0.7(4) \\
89 \pm 0.3(4)\end{array}$ & $\begin{array}{l}\text { n.s. } \\
<0.01 \\
<0.001\end{array}$ & $\begin{array}{l}80 \pm 1.6(12) \\
52 \pm 4.7(6) \\
79 \pm 2.5(13)\end{array}$ & $\begin{array}{l}\text { n.s. } \\
\text { n.s. } \\
\text { n.s. }\end{array}$ & $\begin{aligned} & 63 \pm 0.5(17) \\
&- \\
& 80 \pm 1.7(4)\end{aligned}$ & $\begin{array}{c}<0.001 \\
- \\
\text { n.s. }\end{array}$ \\
\hline $\begin{array}{l}10 \mathrm{~m} M \text { Serine } \\
10 \mathrm{~m} M \text { Proline } \\
10 \mathrm{~m} M \text { Cycloleucine }\end{array}$ & $\begin{array}{l}78 \pm 1.0(4) \\
37 \pm 2.6(4) \\
76 \pm 1.0(4)\end{array}$ & $\begin{array}{l}86 \pm 0.5(4) \\
58 \pm 2.1(4) \\
87 \pm 1.3(8)\end{array}$ & $\begin{array}{l}<0.001 \\
<0.001 \\
<0.001\end{array}$ & $\begin{array}{l}81 \pm 2.2(10) \\
61 \pm 0.7(35) \\
80 \pm 0.4(33)\end{array}$ & $\begin{array}{l}\text { n.s. } \\
\text { n.s. } \\
<0.001\end{array}$ & $\begin{array}{l}66 \pm 0.5(11) \\
43 \pm 2.9(14) \\
72 \pm 1.2(16)\end{array}$ & $\begin{array}{l}<0.001 \\
<0.001 \\
<0.001\end{array}$ \\
\hline $\begin{array}{l}10 \mathrm{~m} M \text { Leucine } \\
10 \mathrm{~m} M \text { Isoleucine } \\
10 \mathrm{~m} M \text { Valine }\end{array}$ & $\begin{array}{l}34 \pm 4.6(7) \\
27 \pm 2.9(6) \\
23 \pm 5.0(4)\end{array}$ & $\begin{array}{l}57 \pm 1.5(19) \\
45 \pm 2.4(12) \\
53 \pm 2.3(10)\end{array}$ & $\begin{array}{l}<0.001 \\
<0.001 \\
<0.001\end{array}$ & $\begin{array}{l}56 \pm 0.9(24) \\
68 \pm 2.2^{b}(16) \\
61 \pm 2.3(31)\end{array}$ & $\begin{array}{l}\text { n.s. } \\
<0.001 \\
\text { n.s. }\end{array}$ & $\begin{array}{l}78 \pm 1.4(6) \\
53 \pm 3.9(9) \\
79 \pm 1.3(6)\end{array}$ & $\begin{array}{l}<0.001 \\
<0.01 \\
<0.01\end{array}$ \\
\hline $\begin{array}{l}10 \mathrm{~m} M \text { Phenylalanine } \\
10 \mathrm{~m} M \text { Glycine } \\
10 \mathrm{~m} M \text { Sarcosine }\end{array}$ & $\begin{array}{l}27 \pm 5.1(11) \\
51 \pm 3.2(4) \\
44 \pm 2.9(14)\end{array}$ & $\begin{array}{l}50 \pm 2.0(16) \\
65 \pm 1.4(4) \\
48 \pm 0.9(14)\end{array}$ & $\begin{array}{c}<0.001 \\
<0.01 \\
\text { n.s. }\end{array}$ & $\begin{array}{l}55 \pm 1.6(30) \\
70 \pm 0.7^{c}(14) \\
50 \pm 2.1^{c}(16)\end{array}$ & $\begin{array}{c}\text { n.s. } \\
<0.01 \\
\text { n.s. }\end{array}$ & $\begin{array}{c}64 \pm 3.2(6) \\
60 \pm 1.5(11) \\
-\end{array}$ & $\begin{array}{c}<0.05 \\
<0.001 \\
-\end{array}$ \\
\hline
\end{tabular}

AIB was at $1 \mathrm{~m} M$ and incubation time was $30 \mathrm{~min}$, except both 30 and $60 \mathrm{~min}$ incubations were used with 14-day tissues. Results are given as inhibition of the distribution ratios produced by the inhibitory conditions, expressed as a percent of the control distribution ratio (absence of inhibitor) at each age. Control distribution ratios for AIB are given in Table 1. Values are averages \pm SEM for the number of samples given in parentheses in each case.

${ }^{a}$ n.s. = not significant statistically $(p>0.05)$.

b Values obtained from 30 min incubations only.

c Values obtained from $60 \mathrm{~min}$ incubations only. 
TABLE 3. Inhibition of MeAIB transport by different agents and conditions in brain slices from rats aged $1,6,14$, and 23 days

\begin{tabular}{|c|c|c|c|c|c|c|c|}
\hline \multirow[b]{2}{*}{ Inhibitor } & \multicolumn{7}{|c|}{$\%$ Inhibition of MeAIB uptake at age } \\
\hline & 1 Day & 6 Days & $\begin{array}{l}\text { p versus } \\
1 \text { day }\end{array}$ & 14 Days & $\begin{array}{c}p \text { versus } \\
6 \text { days }\end{array}$ & 23 Days & $\begin{array}{l}p \text { versus } \\
14 \text { days }\end{array}$ \\
\hline $\mathrm{Na}^{+}$-free medium & $89 \pm 0.9(6)$ & $91 \pm 0.8(12)$ & n.s. ${ }^{a}$ & $92 \pm 0.6(6)$ & n.s. & $91 \pm 2.4(6)$ & n.s. \\
\hline Incubate at $18^{\circ} \mathrm{C}$ & - & $98 \pm 0.6(6)$ & - & $92 \pm 1.4(6)$ & $<0.01$ & $86 \pm 0.8(6)$ & $<0.01$ \\
\hline pH 5.4 (Pi buffer) & $69 \pm 2.9(6)$ & $35 \pm 2.9(6)$ & $<0.001$ & $35 \pm 4.1(6)$ & n.s. & $45 \pm 4.0(6)$ & n.s. \\
\hline $10 \mathrm{~m} M$ AIB & $77 \pm 1.1(6)$ & $77 \pm 1.2(12)$ & n.s. & $46 \pm 6.7(6)$ & $<0.001$ & $33 \pm 2.7(6)$ & n.s. \\
\hline $10 \mathrm{~m} M$ MeAIB & $75 \pm 2.1(6)$ & $66 \pm 3.5(12)$ & n.s. & $58 \pm 1.5(6)$ & n.s. & - & - \\
\hline $10 \mathrm{~m} M$ Alanine & $85 \pm 0.4(6)$ & - & - & $62 \pm 1.7(6)$ & $<0.001^{b}$ & $63 \pm 3.4(6)$ & n.s. \\
\hline $10 \mathrm{~m} M$ Leucine & - & $19 \pm 4.6(16)$ & - & $37 \pm 3.6(6)$ & $<0.05$ & $39 \pm 3.3(6)$ & n.s. \\
\hline $10 \mathrm{~m} M$ Valine & $46 \pm 3.1(6)$ & $20 \pm 2.6(12)$ & $<0.001$ & $56 \pm 1.8(6)$ & $<0.001$ & $28 \pm 3.4(6)$ & $<0.001$ \\
\hline $10 \mathrm{~m} M$ Phenylalanine & $61 \pm 1.6(6)$ & $21 \pm 2.6(6)$ & $<0.001$ & $18 \pm 1.5(14)$ & n.s. & $27 \pm 2.4(6)$ & $<0.01$ \\
\hline
\end{tabular}

MeAIB was at $1 \mathrm{~m} M$ and incubation time was $30 \mathrm{~min}$. Values were calculated as described in the legend to Table 1. Control distribution ratios for MeAIB are given in Table 1. Values are averages \pm SEM for the number of samples given in parentheses in each case.

${ }^{a}$ n.s. = not significant statistically (p $>0.05$ )

${ }^{b}$ Compared with 1-day value (column 2 ).

by decreased $\mathrm{pH}$ or addition of $\mathrm{AIB}$, alanine, or phenylalanine (Table 3, lines 3, 4, 6, and 9); the sharp drop with age in effectiveness on alanine uptake of decreased temperature or addition of AIB or MeAIB, as well as the changes in effects of decreased $\mathrm{pH}$ or $10 \mathrm{mM}$ isoleucine or phenylalanine (Table 4, lines 2, 4, 5, 3, 11, and 13); and the agerelated changes in leucine transport produced by omitting $\mathrm{Na}^{+}$or by adding alanine, valine, or AIB (Table 5, lines $1,6,8$, and 4 ).

The results also show that no two of the test amino acids used the same transport systems to the same extent at any of the ages studied, except for AIB and MeAIB at 1 and 6 days. This conclusion is based on comparisons of the effects of the various inhibitors on the four test amino acids, taken two at a time, and using the data of Tables 2-5. Figure 5 illustrates the type of result obtained, a comparison of the effects of the six inhibitory conditions tested on both AIB and MeAIB in 1-day-old brain (data in Table 2, column 2 versus those in Table 3 , column 2). A highly significant correlation of effects is given $(\mathrm{p}<0.01)$, with none of the points on the graph showing a significant deviation from the regression line calculated for either parameter. The slope of the line is not 1.00 , since a decreased $\mathrm{pH}$ and $10 \mathrm{~m} M$ valine or phenylalanine all had a greater effect on MeAIB uptake than on AIB uptake. Such

TABLE 4. Inhibition of alanine transport by different agents and conditions in brain slices from rats aged $1,6,14$, and 23 days

\begin{tabular}{|c|c|c|c|c|c|c|c|}
\hline \multirow[b]{2}{*}{ Inhibitor } & \multicolumn{7}{|c|}{$\%$ Inhibition of alanine uptake at age } \\
\hline & 1 Day & 6 Days & $\begin{array}{l}p \text { versus } \\
1 \text { day }\end{array}$ & 14 Days & $\begin{array}{l}p \text { versus } \\
6 \text { days }\end{array}$ & 23 Days & $\begin{array}{l}p \text { versus } \\
14 \text { days }\end{array}$ \\
\hline $\mathrm{Na}^{+}$-free medium & $78 \pm 3.9(6)$ & $84 \pm 0.9(5)$ & n.s. ${ }^{a}$ & $87 \pm 1.2(6)$ & n.s. & - & - \\
\hline Incubate at $18^{\circ} \mathrm{C}$ & $70 \pm 1.2(6)$ & $73 \pm 2.2(12)$ & n.s. & $38 \pm 3.4(15)$ & $<0.001$ & - & - \\
\hline pH 5.4 (Pi buffer) & $23 \pm 2.7(11)$ & $17 \pm 1.1(13)$ & $<0.05$ & $-2 \pm 7.8(6)$ & $<0.01$ & $63 \pm 1.9(6)$ & $<0.001$ \\
\hline $10 \mathrm{~m} M \mathrm{AIB}$ & $57 \pm 1.5(3)$ & $50 \pm 2.1(5)$ & $<0.05$ & $26 \pm 2.0(6)$ & $<0.001$ & $35 \pm 2.1(6)$ & $<0.02$ \\
\hline $10 \mathrm{~m} M$ MeAIB & $30 \pm 3.3(6)$ & $26 \pm 2.8(6)$ & n.s. & $20 \pm 3.3(6)$ & n.s. & $1 \pm 5.3$ & $<0.02$ \\
\hline $10 \mathrm{~m} M$ Alanine & $79 \pm 1.0(3)$ & $83 \pm 1.7(6)$ & n.s. & $76 \pm 1.1(6)$ & $<0.01$ & $79 \pm 3.5(6)$ & n.s. \\
\hline $10 \mathrm{~m} M$ Serine & $80 \pm 0.7(6)$ & $81 \pm 0.8(6)$ & n.s. & $58 \pm 1.0(6)$ & $<0.001$ & - & - \\
\hline $10 \mathrm{~m} M$ Proline & $60 \pm 2.2(6)$ & $70 \pm 1.5(12)$ & $<0.01$ & $51 \pm 1.8(6)$ & $<0.001$ & - & - \\
\hline $10 \mathrm{~m} M$ Cycloleucine & $66 \pm 1.1(6)$ & $68 \pm 0.6(6)$ & n.s. & $50 \pm 3.5(6)$ & $<0.001$ & - & - \\
\hline $10 \mathrm{~m} M$ Leucine & $46 \pm 3.0(10)$ & $43 \pm 1.5(6)$ & n.s. & $45 \pm 2.4(6)$ & n.s. & $62 \pm 1.7(12)$ & $<0.001$ \\
\hline $10 \mathrm{~m} M$ Isoleucine & $25 \pm 1.5(18)$ & $36 \pm 2.7(6)$ & $<0.01$ & $43 \pm 3.4(6)$ & n.s. & - & - \\
\hline $10 \mathrm{~m} M$ Valine & $56 \pm 3.1(6)$ & $69 \pm 1.0(6)$ & $<0.01$ & $65 \pm 1.1(6)$ & n.s. & $63 \pm 3.3(6)$ & n.s. \\
\hline $10 \mathrm{~m} M$ Phenylalanine & $19 \pm 7.6(6)$ & $39 \pm 2.5(6)$ & $<0.05$ & $32 \pm 3.7(6)$ & n.s. & $53 \pm 3.0(6)$ & $<0.01$ \\
\hline
\end{tabular}

Alanine was at $0.5 \mathrm{mM}$ and incubation time was $30 \mathrm{~min}$. Values were calculated as described in the legend to Table 1 . Control distribution ratios for alanine were: 1 day, $19.22 ; 6$ days, 33.23; 14 days, $18.29 ; 23$ days, 14.88. Values are averages \pm SEM for the number of samples given in parentheses.

${ }^{a}$ n.s. $=$ not significant statistically $(\mathrm{p}>0.05)$. 
a result would be expected for the inhibitor amino acids, valine and phenylalanine, if AIB had a relatively higher affinity for the common transport carrier(s) than did MeAIB.

Similar calculations were made comparing inhibitory effects on uptakes of the four test amino acids with each other at each age studied. Only with AIB versus MeAIB at both 1 and 6 days was a high correlation coefficient given, along with small deviation of individual points from the regression lines (correlation coefficient at 6 days was $0.95, \mathrm{p}<$ 0.001 ). We therefore conclude that these four amino acids did not use the same transport systems in the same proportion in any other case examined. The characteristics of uptakes of alanine and leucine were distinct from each other and from those of AIB and MeAIB at all four ages studied, while transports of AIB and MeAIB showed some significant differences from each other in both the 14and 23-day-old brain slices and were the same only at 1 and 6 days.

\section{Kinetics of transports of $\mathrm{AIB}$ and MeAIB at different ages}

Transport kinetics were determined by measuring uptakes of $0.1-60 \mathrm{~m} M$ levels of the two amino acids in $10 \mathrm{~min}$ incubations, since uptake was linear for both of them at this time (Fig. 3). The LineweaverBurk plots for AIB are shown in Fig. 6 (for slices from 1- and 6-day-old rats) and Fig. 7 (14- and 23day-old rats). Data for MeAIB (obtained at 6 and 14 days) gave plots of the same type found for AIB at these ages. A single straight line described the uptake in 6-day tissues for both amino acids. In all other cases two separate lines could be calculated from the data, which showed slopes and, in most cases, intercepts on the ordinate (the $1 / \mathrm{v}_{\mathrm{o}}$ axis) that were significantly different from each other. The nonlinear uptake of these amino acids suggests that each of them uses more than one transport system in tissues of these ages (shown for AIB at 1, 14, and 23 days and for MeAIB at 14 days). It should be noted also that there is not great separation of the two lines found for AIB in the 14-day-old tissues and that its saturable uptake at 14 and 23 days is almost identical at low AIB levels and different only at high levels (Fig. 7).

AIB transport by the single system it uses at 6 days had a $K_{\mathrm{m}}$ of $1.0 \pm 0.1 \mathrm{~m} M$ and a $V_{\max }$ of 16.4 $\pm 1.0 \mu \mathrm{mol} / \mathrm{ml}$ of intracellular water per $10 \mathrm{~min}$. Values for MeAIB at 6 days were: $K_{\mathrm{m}} 3.8 \pm 0.5$ $\mathrm{m} M$ and $V_{\max } 19.5 \pm 1.5 \mu \mathrm{mol} / \mathrm{ml}$ of intracellular water per $10 \mathrm{~min}$. These numbers were calculated from Eadie-Hofstee plots, but similar values were obtained from the Lineweaver-Burk plots. The significantly lower $K_{\mathrm{m}}$ for AIB uptake compared with MeAIB is consistent with the finding from the inhibition data, noted above, that AIB has a higher affinity for their common transport carrier than does MeAIB.

\section{DISCUSSION}

The results show that major changes occur in uptake of the amino acids tested over the first three weeks after birth of the rats. Of the seven amino acids used, largest effects were found for AIB, MeAIB, and alanine. The more detailed study of their uptakes, plus that of leucine, shows that the neutral $\alpha$-amino acids undoubtedly are transported by systems A, ASC, and/or $L$ in rat brain slices at all ages studied. These systems have been found in fetal, newborn, and adult mouse brain (Sershen and Lajtha, 1979), and the present results are consistent

TABLE 5. Inhibition of leucine transport by different agents and conditions in brain slices from rats aged $1,6,14$, and 23 days

\begin{tabular}{|c|c|c|c|c|c|c|c|}
\hline \multirow[b]{2}{*}{ Inhibitor } & \multicolumn{7}{|c|}{$\%$ Inhibition of leucine uptake at age } \\
\hline & 1 Day & 6 Days & $\begin{array}{l}p \text { versus } \\
1 \text { day }\end{array}$ & 14 Days & $\begin{array}{c}p \text { versus } \\
6 \text { days }\end{array}$ & 23 Days & $\begin{array}{l}p \text { versus } \\
14 \text { days }\end{array}$ \\
\hline $\mathrm{Na}^{+}$-free medium & $59 \pm 0.9(6)$ & $72 \pm 1.9(6)$ & $<0.001$ & - & - & $85 \pm 1.0(6)$ & $<0.001^{c}$ \\
\hline Incubate at $18^{\circ} \mathrm{C}$ & $50 \pm 1.8(6)$ & $56 \pm 4.0(6)$ & n.s. ${ }^{b}$ & $50 \pm 2.5(6)$ & n.s. & $76 \pm 4.6(6)$ & $<0.001$ \\
\hline pH 5.4 (Pi buffer) & $-44 \pm 2.1^{a}(6)$ & $-50 \pm 1.7^{a}(6)$ & n.s. & $-4 \pm 8.0(6)$ & $<0.001$ & $-13 \pm 4.2^{a}(6)$ & n.s. \\
\hline $10 \mathrm{~m} M \mathrm{MeAIB}$ & $17 \pm 0.6(5)$ & $19 \pm 2.0(6)$ & n.s. & $42 \pm 4.0(6)$ & $<0.001$ & $27 \pm 3.5(6)$ & $<0.02$ \\
\hline $10 \mathrm{~m} M$ Alanine & $-17 \pm 4.9^{a}(6)$ & $10 \pm 5.8(11)$ & $<0.01$ & $36 \pm 2.6(6)$ & $<0.01$ & $53 \pm 1.8(6)$ & $<0.001$ \\
\hline $10 \mathrm{~m} M$ Leucine & $36 \pm 4.1(6)$ & $39 \pm 3.1(6)$ & n.s. & $57 \pm 2.2(8)$ & $<0.001$ & - & - \\
\hline $10 m M$ Valine & $4 \pm 6.6(5)$ & $28 \pm 0.8(15)$ & $<0.001$ & $48 \pm 3.7(6)$ & $<0.001$ & $54 \pm 1.4(6)$ & n.s. \\
\hline $10 \mathrm{~m} M$ Phenylalanine & - & $48 \pm 2.3(10)$ & - & $53 \pm 1.7(6)$ & n.s. & $70 \pm 4.3(6)$ & $<0.01$ \\
\hline
\end{tabular}

Leucine was at $1 \mathrm{~m} M$ and incubation time was $30 \mathrm{~min}$. Values were calculated as described in the legend to Table 1 . Control distribution ratios for leucine were: 1 day, 3.36; 6 days, $4.92 ; 14$ days, $5.92 ; 23$ days, 7.86 . Values are averages \pm SEM for the number of samples given in parentheses.

${ }^{a}$ A negative value is given when the uptake was stimulated rather than inhibited.

${ }^{b}$ n.s. = not significant statistically $(\mathrm{p}>0.05)$.

c Compared with 6-day value (column 3 ). 


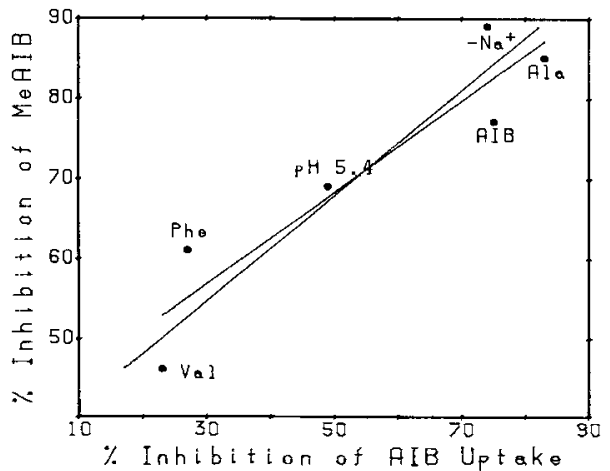

FIG. 5. Comparison of effects of inhibitory conditions on uptakes of AIB and MeAIB in brain slices from 1-day-old rats. Test amino acids were at $1 \mathrm{mM}$ and incubation time was 30 min. Inhibitory amino acids were present at $10 \mathrm{mM}$. Standard abbreviations are used for the amino acids. $-\mathrm{Na}^{+}$, incubation in the absence of $\mathrm{Na}^{+}$in the medium; $\mathrm{pH} 5.4$, incubation in Krebs-Ringer phosphate buffer at this $\mathrm{pH}$. The two lines were calculated by the method of least squares and represent the lines of best fit based on the deviations on both the $x$ and $y$ axes. Correlation coefficient for the points is 0.93 ( $p$ $<0.01$ ). None of the points deviated significantly from either of the lines of best fit, as drawn. The data plotted are taken from the second columns of Tables 2 and 3 .

with their presence in rat brain from birth. An analysis of the inhibition and kinetic results permits at least a partial description of the changes that occur in these systems as the donor rats age from 1 to 23 days old.

The pattern of inhibition of MeAIB uptake in the brain slices is that characteristic of system $A$ at all

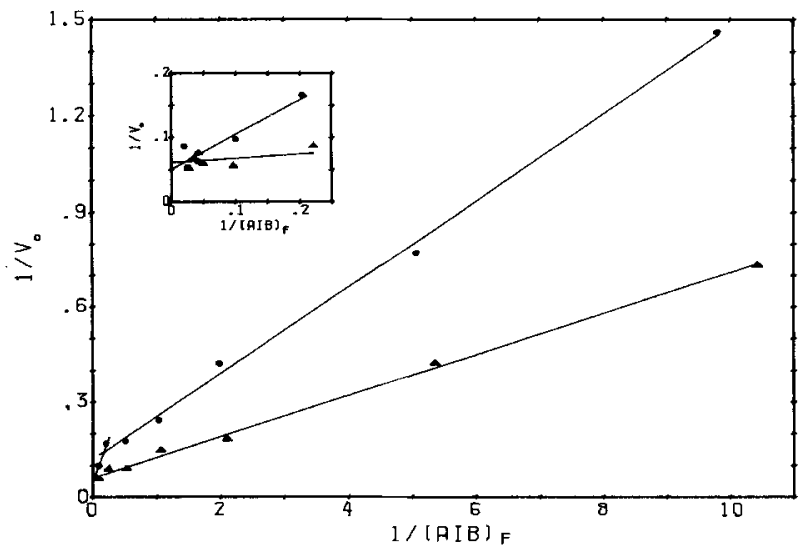

FIG. 6. Reciprocal (Lineweaver-Burk) plots of saturable entry of different levels of AlB into brain slices from 1- and 6-dayold rats. AlB was at 0.1 to $40 \mathrm{mM}$ levels and incubation time was $10 \mathrm{~min}$. Nonsaturable entry $(0.09 / 10 \mathrm{~min}$ at 1 day and $0.05 / 10 \mathrm{~min}$ at 6 days) was calculated by the method of Akedo and Christensen (1962) and subtracted from total uptake to give saturable entry $\left(v_{0}\right)$ in $\mu \mathrm{mol} / \mathrm{ml}$ of intracellular water per $10 \mathrm{~min}$. O, 1-day tissues; $\Delta, 6$ day tissues. The lines were calculated by the method of least squares. Slopes of the two lines calculated for 1 day were significantly different from one another $(p<0.01)$. Two to seven values were averaged for each point at 1 day; $2-12$ values were averaged for each point at 6 days.

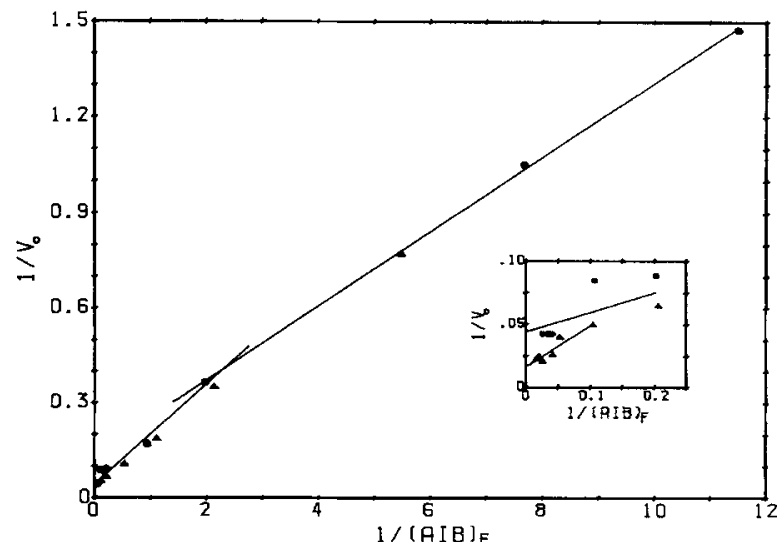

FIG. 7. Reciprocal (Lineweaver-Burk) plots of saturable entry of different levels of AIB into brain slices from 14- and 23day-old rats. AIB was at 0.08 to $60 \mathrm{mM}$ levels and incubation time was $10 \mathrm{~min}$. Nonsaturable entry $(0.13 / 10 \mathrm{~min}$ at 14 days $0.06 / 10$ min at 23 days) was subtracted from total uptake to obtain saturable entry $\left(v_{0}\right)$ in $\mu \mathrm{mol} / \mathrm{ml}$ of intracellular water per $10 \mathrm{~min}$. - 14-day tissues; $\boldsymbol{\Delta}, 23$-day tissues. The lines were calculated by the method of least squares. Two lines, with significantly different slopes and y intercepts, were calculated at each age $(p<0.01$ to $p<0.001)$. Only the lines for 14-day tissues are drawn on the large graph; lines from both ages are shown in the inset. Two to nine values were averaged for each point at 14 days; $2-7$ values were averaged per point at 23 days.

ages studied. This fact in itself is not surprising, since MeAIB transport is generally limited extensively or exclusively to system A in most tissues (Christensen, 1975). Furthermore, in the tissues from 6-day-old rats, the Lineweaver-Burk plot does not suggest more than one system for this amino acid. If this is indeed the case, we may conclude that MeAIB uptake at this age is limited to system A, within the limits of detection. Very similar characteristics were found for uptake of the amino acid at 1 day and 6 days; however, significantly greater inhibition was given by a decreased $\mathrm{pH}$ and by valine and phenylalanine at 1 day than at 6 days (Table 3 , column 2 versus column 3 ). These differences are likely due to use of a second system by MeAIB at 1 day. The evidence suggests that AIB used two systems at 1 day (see Fig. 6) and also that AIB and MeAIB used the same systems in the 1-day-old tissues (Fig. 5). Hence, we may conclude that MeAIB also used these same two systems at 1 day. The development from 1 day to 6 days, therefore, resulted in disappearance of one system used by MeAIB. In addition, uptake at 6 days was much greater than at 1 day. Therefore, we may conclude that there was an increased amount of transport by system $A$ as the brain aged from 1 day to 6 days old.

The results with AIB were very similar to those for MeAIB over this same age period, with only minor differences. AIB used the same two systems at 1 day as did MeAIB (Fig. 5). It used only one system at 6 days (Fig. 6), and this latter system 
appeared to be the same one used by MeAIB at this age, i.e., system $A$.

Alanine uptake, on the other hand, showed about the same characteristics at 1 day as at 6 days, but its transport inhibitory pattern was significantly different from any of the others. Its high $\mathrm{Na}^{+}$sensitivity (Table 4) suggests that it probably used an ASC-like system at these ages. The increase in system A activity by 6 days could account at least partly for the increase in alanine uptake by this time, since alanine would be expected to use this system.

Aging of the tissue beyond 6 days led to a decline in uptakes of AIB, MeAIB, and alanine at the low levels used in most of the experiments. Although the general characteristics of these transports remained about the same as in 6-day tissues, several significant differences occurred by day 14 , the most prominent one being the apparent appearance of a second system for both AIB and MeAIB. Transports of these two amino acids was also different from one another at 14 days. The drop-off in total uptake can mean only a decreased use of system A (since this is the only system these amino acids use at 6 days), presumably the result of a decrease in its amount. The second system used at 14 days is likely L. Both AIB and MeAIB inhibited leucine uptake about twice as much at 14 days as earlier (Table 5). In addition, AIB uptake was inhibited increasingly by the L-system amino acids as the donor rat aged (Table 2, lines 10-13). This type of progression suggests that system L activity increased with aging, especially after 6 days, and/or that AIB increased its use of system $L$ over this time.

An increase in system $L$ with age is also suggested by the fact that leucine uptake continued to increase over the entire period studied here, 1-23 days (Fig. 2). Leucine appeared also to use system $\mathrm{A}$ and/or ASC to some extent at all ages, however, as shown by its high $\mathrm{Na}^{+}$sensitivity $(60 \%$ at 1 day and increasing to $85 \%$ by 23 days, Table 5). This increase undoubtedly represents progressively greater uptake by system ASC, since the results (discussed above) suggest that system A activity declined after day 6 .

The kinetics of AIB and MeAIB uptakes provide further information about the changes in brain transport systems with development. A comparison of the Lineweaver-Burk curves for AIB uptake at 6 days (Fig. 6) and 14 days (Fig. 7) shows that both the slopes and $y$ intercepts are different from one another, whether one considers the 14-day results to follow a single line or the two lines drawn in Fig. 7. Furthermore, the differences represent increases in both gross $K_{\mathrm{m}}$ (negative inverse $\mathrm{x}$ intercept) and gross $V_{\max }$ (inverse y intercept) with aging from 6 to 14 days, a situation resulting in greater AIB up- take at low levels in 6-day tissues and greater uptake at high levels at 14 days, as noted earlier. Since the results suggest that system $A$ activity decreased with aging over this time, we may conclude that the second system, appearing after 6 days and by 14 days, has a higher $V_{\max }$ for AIB than does system A. Furthermore, the change in gross $K_{\mathrm{m}}$ in itself suggests that AIB is using a new system, i.e., one with a different affinity for the amino acid. For MeAIB the lower uptake at 14 days than at 6 days at all levels was associated with a lower gross $V_{\max }$ at the older age.

A comparison of the Lineweaver-Burk plots for AIB transport at 1 and 6 days (Fig. 6) shows that uptake at high levels was not greatly different at these two ages, but that much greater uptake was observed in the 6-day tissues than at 1 day when low levels of the amino acid were used (i.e., below about $5 \mathrm{mM}$ ). This increase in a relatively low $K_{\mathrm{m}}$ system corresponds to the increase in use of system A over this age. Figure 7 shows, on the other hand, that aging from 14 to 23 days did not result in clear differences in AIB uptake until high levels were used, i.e., somewhat greater uptake was found at 23 days than at 14 days only at levels above about $10 \mathrm{mM}$ (see inset in Fig. 7). If this is indeed the case, the results provide further evidence for a change in the transport systems used by AIB over this age, with an increase in the amount of a high $K_{\mathrm{m}}$ system, which is probably system L.

The four age groups chosen for study are, of course, arbitrary and are only points used to indicate the over-all changes that occur in the transport systems with brain development. Nevertheless, the above results suggest the general patterns of these changes. An A-like system is present at birth, increases in activity from 1 to 6 days, and then declines by day 14. System L, in contrast, appears to increase regularly with aging of the brain, while system ASC probably also increases its activity with aging, although its pattern of change is less clear. The high system A activity at 6 days may make it difficult to demonstrate that AIB or MeAIB uses more than one system at that age (if, indeed, they do), even though the other systems are present then.

The inhibition results reported here for 1-day-old brain slices are similar to those of Sershen and Lajtha (1979), who showed the effects of several inhibitory conditions on uptakes of amino acids in brain slices from fetal, newborn, and adult mice. These workers concluded that systems L and ASC were fully developed in the fetal tissue, but that system A showed developmental changes after birth. However, they did not measure transport in tissues between birth ( 1 day) and adult. It is difficult to explain the results reported here in terms of changes in only one of the transport systems used 
by all four test amino acids we studied. The work of Sershen and Lajtha suggests the presence of at least 10 amino acid transport systems in mouse brain, including those for the neutral and acidic acids and those for specific amino acids such as $\gamma$ aminobutyric acid. If the transport systems in rat brain are as complex as those in the mouse, changes, such as found here, with development are perhaps not surprising.

Acknowledgment: This work was supported in part by grant AM-03709 from the National Institutes of Health, U.S. Public Health Service. The authors wish to thank Ann Johnson for her technical assistance with part of this work.

\section{REFERENCES}

Akedo H. and Christensen H. N. (1962) Nature of insulin action on amino acid uptake by the isolated diaphragm. J. Biol. Chem. 237, 118-122.

Christensen H. N. (1975) Biological Transport, 2nd ed., pp. 176179. W. A. Benjamin, Reading, Massachusetts.

Dobbing J. (1971) Undernutrition and the developing brain: the use of animal models to elucidate the human problem, in Advances in Experimental Medicine and Biology, Vol. 13. Chemistry and Brain Development (Paoletti R. and Davison A. N., eds), pp. 399-412. Plenum Press, New York.

Geel S. E., Valcana T., and Timiras P. S. (1967) Effect of neo- natal hypothyroidism and of thyroxine on $\mathrm{L}-\left[{ }^{14} \mathrm{C}\right] l e u c i n e$ incorporation in protein in vivo and the relationship to ionic levels in the developing brain of the rat. Brain Res. 4, $143-150$.

Gelber S., Campbell P. L., Deibler G. E., and Sokoloff L. (1964) Effects of L-thyroxine on amino acid incorporation into protein in mature and immature rat brain. $J$. Neurochem. 11, 221-229.

Guidotti G. G., Borghetti A. F., and Gazzola G. C. (1978) The regulation of amino acid transport in animal cells. Biochim. Biophys. Acta 515, 329-366.

Hamburgh M., Lynn E., and Weiss E. P. (1964) Analysis of the influence of thyroid hormone on prenatal and postnatal maturation of the rat. Anat. Rec. 150, 147-162.

Levi G. (1973) Development of amino acid transport systems in incubated tissue, in Biochemistry of the Developing Brain, Vol. 1 (Himwich W., ed), pp. 187-218. Marcel Dekker, New York.

Piccoli F. (1976) Changes in cerebral amino acid transport during development, in Transport Phenomena in the Nervous System (Levi G., Battistin L., and Lajtha A., eds), pp. 405411. Plenum Press, New York.

Riggs T. R. and Pan M. W. (1972) Transport of amino acids into the oestrogen-primed uterus. Enchancement of the uptake by a preliminary incubation. Biochem. J. 128, 19-27.

Riggs T. R., Pote K. G., Im H.-S., and Huff D. W. (1984) Thyroxine-induced changes in the development of neutral $\alpha$ amino acid transport systems of rat brain. J. Neurochem. $42,1260-1268$.

Sershen H. and Lajtha A. (1979) Inhibition pattern of analogs indicates the presence of ten or more transport systems for amino acids in brain cells. $J$. Neurochem. 32, 719-726. 